\title{
EM BUSCA DA FLOR VIVA: PARA UMA CRÍTICA AO IDEÁRIO INCLUSIVISTA EM EDUCAÇÃO
}

\author{
GIOVANI FERREIRA BEZERRA* \\ Doracina Aparecida de Castro Araujo*
}

O apelo para que eles [os homens] deixem as ilusões a respeito da sua situação é o apelo para abandonarem uma situação que precisa de ilusões. (Karl Marx, 1844)

\begin{abstract}
RESUMO: O presente texto investiga a constituição e os desdobramentos ideológicos do ideário inclusivista em educação, no contexto do avanço neoliberal. O tratamento dos dados obtidos, resultantes de uma pesquisa bibliográfica em andamento, é crítico-dialético e adota pressupostos marxistas. As análises realizadas situam a inclusão escolar de pessoas com deficiência no bojo de tentativas reformistas do capitalismo, com vistas à sua perpetuação hegemônica. Conquanto preocupe-se mais em denunciar as apropriações neoliberais e pós-modernas da autêntica luta pelo reconhecimento dos direitos das pessoas com deficiência, o artigo sugere a necessidade de uma práxis revolucionária, comprometida com a emancipação e o pleno desenvolvimento de todas as pessoas, com ou sem deficiências.
\end{abstract}

Palavras-chave: Inclusão escolar. Neoliberalismo. Capitalismo.

IN SEARCH OF THE LIVE FLOWER:

\section{A CRITIQUE OF THE IDEAS FOR INCLUSIVE EDUCATION}

ABSTRACT: This paper investigates the constitution and ideological unfolding of the inclusive ideals in education in the context of neoliberal advance. The data obtained as a result of literature research still in progress, is examined under a critical-dialectical perspective and adopts Marxist assumptions. The analyses situate school inclusion of disabled people in the midst of capitalism reformist attempts, which aim at perpetuating their hegemony. While the major concern is to report neoliberal and postmodern appropriations of the authentic struggle for the recognition of the rights of people with disabilities, the article suggests the need for a revolutionary praxis,

\footnotetext{
* Mestre em Educação e professor assistente na Universidade Federal de Mato Grosso do Sul (UFMS), campus de Naviraí. E-mail: gfbezerra@gmail.com

* Doutora em Educação, coordenadora e professora do Programa de Pós-Graduação stricto sensu em Educação da Universidade Estadual de Mato Grosso do Sul (Uems). E-mail: doracina@gmail.com
} 
committed to the emancipation and full development of every individual, with or without disabilities.

Key words: School inclusion. Neoliberalism. Capitalism.

\section{À la RECHERCHE DE LA FLEUR ViVANTE: POUR UNE CRITIQUe AUX IDÉES D'INCLUSION DANS L'ENSEIGNEMENT}

RÉSUMÉ: Cet article se prpose d'examiner la constitution et les dépliages idéologiques des idéaux d'inclusion dans l'enseignement, dans le contexte du progrès néolibéral. Le traitement des données obtenues, résultant d'une recherche bibliographique qui est en train de se faire, est dialectique-critique et adopte des conjectures marxistes. Les analyses réalisées placent l'inclusion scolaire des individus handicapés dans le milieu de tentatives réformistes du capitalisme, avec des vues à leur perpétuation hégémonique. Bien qu'il s'inquiète à dénoncer les appropriations néolibérales et les postmodernes du combat authentique pour la reconnaissance des droits des personnes handicapées, l'article suggère la nécessité d'une práxis révolutionnaire, compromise avec l'émancipation et le complet développement de toutes les personnes, avec ou sans les handicaps.

Mots-clés: Inclusion scolaire. Néolibéralisme. Capitalisme.

\section{Introdução}

$\mathrm{N}$

o final dos anos de 1980, surgem, em todo o mundo, reformas educacionais atreladas aos princípios daquilo que, em 1989, se convencionou denominar "Consenso de Washington", em referência às medidas de ajuste estrutural do mercado, recomendadas pelo Fundo Monetário Internacional (FMI), Banco Mundial e Banco Interamericano de Desenvolvimento (Bird) (NEGRÃO, 1998; TORRES, 2009). Nesse cenário, o discurso educacional ganha um tom salvacionista bastante peculiar, forjando-se um projeto político-ideológico que credita à educação, sob a forma mistificada, não só o abrandamento das mazelas sociais, como uma função bastante pragmática no processo de desenvolvimento econômico, marcado pelo uso intensivo de novas tecnologias produtivas. Duarte (2001, p. 47) cita que, "No contexto atualmente travado pelo capitalismo para sua perpetuação, a educação desempenha um importante papel [...]", pois se torna difusora de valores como a solidariedade, a tolerância, sustentabilidade e empreendedorismo individual, vistos como forma de resolver os antagonismos sociais (DELORS, 1998; DUARTE, 2001).

Em tais circunstâncias, passa-se a enfatizar o aspecto humano da educação, seu potencial pacificador, redentor e democrático para a solução dos grandes entraves gestados pelo próprio agravamento da exploração capitalista (DUARTE, op. cit.; MÉSZÁROS, 2008). Não obstante o tom sedutor desse discurso, o intuito, porém, é, "com essa concepção [...] convencer as pessoas de que a exclusão social não seria um processo inerente à economia neoliberal" (DUARTE, op. cit., p. 142). Logo, 
uma simples mudança de perspectiva seria suficiente para resolver os impasses sistêmicos do capitalismo, supostamente invertendo-se o polo de um desenvolvimento econômico sem limites para o polo do desenvolvimento humano sustentável, da cooperação internacional e do aumento das oportunidades educacionais aos diferentes sujeitos (DELORS, op. cit.).

A retórica pós-moderna transforma a educação em um tesouro a descobrir (idem, ibid.) e lhe atribui poderes suficientes para produzir justiça social. No interior dessa conjuntura, a prática escolar "[...] volta novamente a ser encarada como capaz de produzir a superação da exclusão social” (DUARTE, 2001, p. 142), ao mesmo tempo em que "[...] possui a importante tarefa de esconder as contradições do projeto neoliberal de sociedade, isto é, as contradições do capitalismo contemporâneo" (idem, ibid., p. 47), especialmente com a propagação de valorações político-educacionais norteadoras de uma aprendizagem ao longo da vida, marcada pelos pilares do aprender a conhecer, aprender a fazer, aprender a viver juntos e aprender a ser (DELORS, 1998). Do ponto de vista crítico, porém, é preciso entender que

[...] a educação contínua do sistema capitalista tem como cerne a asserção de que a própria ordem social estabelecida não precisa de nenhuma mudança significativa. Precisa apenas de uma "regulação mais exata" em suas margens, que se deve alcançar pela metodologia idealizada do "pouco a pouco". Por conseguinte, o significado mais profundo da educação contínua da ordem estabelecida é a imposição arbitrária da crença na absoluta inalterabilidade de suas determinações estruturais fundamentais. (MÉSZÁROS, 2008 , p. 82 , grifos do autor)

Na esteira deste bloco histórico (GRAMSCI, 1995), marcado pelo neoliberalismo galopante e proposições conciliatórias, deflagradas para minimizar os efeitos de crises globais, cerceando os avanços de um projeto revolucionário, situa-se, pois, a emergência do ideário inclusivista em educação no plano político internacional, com repercussões no Brasil (BEZERRA; ARAUJO, 2010, 2011). Não por acaso, os apelos pela inclusão escolar de pessoas com deficiência emergem, sobretudo, na última década do século XX, não tanto como resposta a possíveis reivindicações coletivas, mas, principalmente, como uma estratégia reformista do capital, sendo um novo mecanismo ideológico para perpetuar a ordem estabelecida e manter o status quo dominante.

No cerne de tal ideário, a base material permanece inconteste, embora se divulgue a ideia de que é possível superar tanto a exclusão, historicamente vivenciada pelas pessoas com deficiência, quanto as contradições capitalistas mais amplas, que perpassam a escola e a sociedade, mediante a lógica mistificadora do reformismo (MÉSZÁROS, 2008). Ao se apresentar como uma perspectiva novidadeira (LOMBARDI, 2008) ou uma personificação carinhosa, engendrada pela dinâmica do capitalismo (MÉSZÁROS, op. cit.), a apologética inclusivista arrebanha a adesão e a militância 
de um grande número de intelectuais, conquanto seus elementos contraditórios e reprodutivistas ainda não tenham sido dialeticamente percebidos e estudados.

A aceitação ingênua de supostas aspirações universais e democráticas oblitera o fato de que "[...] todo sistema de educação orientado à preservação acrítica da ordem estabelecida a todo custo [como é o caso brasileiro] só pode ser compatível com os mais pervertidos ideais e valores educacionais" (MÉSZÁROS, op. cit., p. 83, grifos do autor). Por conseguinte, levantamos a hipótese de que o fenômeno da inclusão também é revelador da tendência que se firma no mundo pós-moderno, pela qual a totalidade das determinações sócio-históricas é abandonada "[...] em nome de uma presumida legitimidade de lidar apenas com manifestações particulares" (idem, ibid., p. 62 , grifos do autor), com ajustes pontuais. Longe de representar uma atitude míope do sistema, isto constitui, por assim dizer, sua ontologia mesma. O objetivo tácito é desviar o foco dos problemas estruturais e dos aspectos contraditórios imanentes à dinâmica capitalista, em especial quando se acentuam as disparidades socioeconômicas e as tensões pela liderança política em escala planetária, ameaçando-se a reprodução metabólica do capital (MÉSZÁROS, 2008).

Sendo assim, este discurso pela inclusão de pessoas com deficiência na escola regular, quando visto à luz dos interesses hegemônicos, é uma variante sociopolítica do reformismo inerente à pós-modernidade; um corretivo tipicamente marginal à lógica dominante (idem, ibid.), a fim de conservá-la, sem ameaçar sua integridade. Apesar da aparência humanística, o propósito essencial do ideário inclusivista é outro. Para compreendê-lo, podem-se aplicar as considerações filosóficas de Mészáros (op. cit.) sobre o comportamento das variedades sociopolíticas do reformismo. Como uma dessas novas variedades, o movimento inclusivista assume, até de modo imperceptível para seus defensores e proponentes, deslocados dos centros de poder, no dia a dia das escolas e no mundo fenômeno das aparências mistificadoras, a função de

[...] tentar desviar a atenção das determinações sistêmicas - que no final das contas definem o caráter de todas as questões vitais - para discussões mais ou menos aleatórias sobre efeitos específicos, enquanto se deixa a sua incorrigível base causal não só incontestavelmente permanente como também omissa. (Idem, ibid., p. 63-64, grifos do autor)

Nessa direção, consideramos urgente uma leitura crítica acerca do fenômeno inclusão escolar, começando pela explicitação de seus nexos orgânicos com a ideologia neoliberal e seu caráter antidialético, apaziguador e a-histórico. Deve-se questionar como um ajuste pontual possa realmente promover uma grande mudança nas relações institucionais e sociais, colocando a escola como agente autônomo em relação aos conflitos de classe e aos objetivos mercadológicos existentes. Afinal, soa no mínimo suspeita a importância crescente dada à categoria de inclusão, certamente não apenas de pessoas com deficiência, mas também de outras "diversidades", 
por um sistema mantido "[...] sob a égide do capitalismo, que faz da exclusão sua premissa ontológica básica, seu critério de funcionalidade” (BEZERRA, 2011, p. 40). Contudo, não se trata de negar a validade de uma proposta educacional aberta às diferenças individuais e ao justo reconhecimento dos direitos das pessoas com deficiência; nem sequer se defende aqui uma posição saudosista quanto às escolas especiais (BEZERRA; ARAUJO, 2010, 2011).

O desafio está em reconhecer a manipulação ideológica implícita a certos slogans do pós-modernismo, graças aos quais “[...] a diferença e a diversidade, dimensões importantes da vida humana, mascaram a violência social da desigualdade e afirmam o mais canibal individualismo" (FRIGOTTO, 2005, p. 71). Desfeitas as ilusões, parece-nos que o ponto fulcral é assumir um compromisso político genuinamente transformador quanto à escolarização das pessoas com deficiência, entendendo esse processo como a síntese de múltiplas determinações (MARX, 1999). Assim, se neste texto esboçamos um posicionamento crítico acerca da escola e da proposta inclusivas, tal como estas se têm concretizado, não nos colocamos como reacionários, tampouco como defensores das práticas escolares segregadoras, que devem ser combatidas teórica e praticamente. Na realidade, filiamo-nos ao pensamento de Barroco (2007, p. 20), segundo quem é

[...] legítima a luta pela observação e respeito à condição que a deficiência e o desenvolvimento diferenciado do curso regular impõem, os quais têm motivado ações muito importantes por parte de diferentes segmentos e organizações, mas é preciso ter claro, também, que o preconceito, o estigma, a lógica da exclusão, etc. apresentam-se às pessoas com base nas condições objetivas e, sem superação das mesmas, a transformação pleiteada não se torna possível nos moldes como se defende e se gostaria.

Em decorrência da perspectiva objetivada por Barroco (2007), inferimos que a verdadeira transformação pressupõe antes o enfrentamento do capital e suas artimanhas, atentando-se às apropriações neoliberais (DUARTE, 2001) de que tem sido alvo o discurso pela inclusão de pessoas com deficiência na escola regular. Por isso, é de suma importância empreender uma breve análise do ideário inclusivista. Tal é o escopo deste artigo, que empreende, a partir de estudos bibliográficos no campo da perspectiva marxista, crítico-dialética, uma breve reflexão sobre a origem, as vinculações e os desdobramentos sociopolíticos e econômicos da proposta inclusiva em educação.

Esperamos contribuir para subsidiar a formação crítica de educadores e pesquisadores, especialmente daqueles que queiram se filiar a uma concepção revolucionária da e na práxis social e pedagógica, não se conformando com reformas paliativas, tampouco com as aparências sedutoras do discurso dominante. Sem negar a importância de garantir aos alunos com deficiência o direito inalienável à educação em uma escola regular, o texto intenta uma leitura mais ampla desse fenômeno, 
como resposta ao idealismo ainda predominante nas interpretações teóricas sobre o assunto. $\mathrm{O}$ trabalho não tem, certamente, a pretensão de esgotar a problemática levantada, porquanto sintetiza apenas resultados parciais de nossa pesquisa de mestrado, que está em andamento, com apoio financeiro da Coordenação de Aperfeiçoamento de Pessoal de Nível Superior (Capes). Contudo, as reflexões ora expostas talvez venham suscitar outras pesquisas e ampliar os debates sobre a educação escolar inclusiva, no interesse da formação docente e da emancipação genérica do homem, com ou sem deficiência.

\section{O ideário inclusivista e seu viés neoliberal}

A gênese e a oficialização daquilo que denominamos ideário inclusivista em educação remontam, no panorama histórico, às proposições político-pedagógicas de inspiração neoliberal resultantes de duas grandes conferências internacionais: a Conferência Mundial sobre Educação para Todos, realizada de 5 a 9 de março de 1990, em Jomtien, na Tailândia (UNESCO, 1990) e a Conferência Mundial sobre Necessidades Educativas Especiais, ocorrida entre 7 e 10 de junho de 1994, em Salamanca, na Espanha (UNESCO, 1994). Da primeira resultou a Declaração Mundial sobre Educação para Todos: satisfação das necessidades básicas de aprendizagem, ao passo que da segunda advieram a Declaração de Salamanca sobre princípios, políticas e práticas na área das necessidades educativas especiais e a Estrutura de Ação em Educação Especial.

Em ambas, pode-se notar a forte participação das agências de regulação global do capitalismo, organismos mundialmente responsáveis pela difusão dos (contra)valores que a este convém. Para se dissipar quaisquer dúvidas, sob o pretexto de que talvez estejamos forçando a análise, recorremos a um trecho da própria Declaração de Salamanca. Em certo ponto do documento, os elaboradores afirmam textualmente que

\footnotetext{
Nós congregamos a comunidade internacional; em particular, nós congregamos: - governos com programas de cooperação internacional, agências financiadoras internacionais, especialmente as responsáveis pela Conferência Mundial em Educação para Todos, Unesco, Unicef, UNPD ${ }^{1}$ e o Banco Mundial:

- a endossar a perspectiva de escolarização inclusiva e apoiar o desenvolvimento da educação especial como parte integrante de todos os programas educacionais [...]. (UNESCO, 1994, n.p.)
}

Os tentáculos do capital estão, portanto, muito claros nas proposições de mudanças educacionais que surgem com vigor nos anos de 1990. Nessa conjuntura, vislumbra-se a plausibilidade da hipótese segundo a qual há "[...] necessidade da escola reorganizar-se para cumprir seu papel político/ideológico de reprodutora 
da concepção de mundo neoliberal, sendo express[ão] dessa reorganização a Conferência Mundial de Educação para Todos [...]" (CASSIN, 2008, p. 164), juntamente com aquela realizada na Espanha, quatro anos depois. Em tais conferências, sobressai a elevada magnitude de intervenção do Banco Mundial nas questões educacionais contemporâneas. Surge, assim, o modelo de educação para todos, por meio do qual se revive um velho credo pedagógico, transmutado como grande novidade: é preciso satisfazer as necessidades de aprendizagem de cada um, pois a educação é propulsora de desenvolvimento socioeconômico pacífico, solidário e equalizador das diferenças individuais.

O próprio termo satisfação está imbuído da lógica neoliberal de mercado, que está sempre preocupada em satisfazer o consumidor e seu direito de consumir (GENTILI, 2009), em agradá-lo para tornar mais cativante a sedução exercida. A proposta não é, pois, radicalizar o debate em torno das desigualdades historicamente estabelecidas, nem promover a socialização completa das forças produtivas a todos os indivíduos. A preocupação central é tão somente "[...] ajudá-los a perceber e a adaptar-se às mudanças sociais e culturais" (UNESCO, 1990, n.p.), a fim de se tornarem trabalhadores flexíveis, permanentemente ajustados aos imperativos das novas formas de acumulação capitalista, haja vista o reordenamento dos postos de trabalho e a onipresença das novas tecnologias (DELORS, 1998; FONSECA apud DUARTE, 2001; KUENZER, 2005).

Não casualmente, a Declaração de Jomtien assinala que, embora exista um "quadro sombrio de problemas" a ser enfrentado pelo mundo todo, a miríade de informações e conhecimentos disponíveis na atualidade, sempre em nível ascendente, traz valiosa contribuição "[...] sobre como melhorar a qualidade de vida ou como aprender a aprender" (UNESCO, 1990, n.p.). Este aprender a aprender não é senão uma manobra ilusionista para assegurar, em tempos de violenta globalização, a inalterabilidade do projeto burguês, alardeando-se princípios capazes de convencer as pessoas quanto à necessidade de dominarem habilidades, valores e atitudes adequados às atuais exigências do processo produtivo (DELORS, 1998; DUARTE, 2001; UNESCO, 1990). Tal ideário cumpre o propósito deliberado de imprimir ao capitalismo as marcas da fluidez e da volatilidade necessárias à sua reprodução, pois a qualquer hora pode-se inverter completamente o caminho assumido e se reclamar a necessidade de outros saberes e fazeres que sejam mais convenientes a dado contexto histórico.

A hegemonia de pressupostos neoliberais impõe às instituições escolares formas empresariais de gerenciamento, levando-se à contenção de gastos públicos e à negação institucional da própria escola, subsumida pela iniciativa privada e pelos tentáculos do capital. Essa situação esteve em maior evidência durante os anos 90 do século passado, quando o ideário neoliberal torna-se hegemônico, após o colapso 
do Estado de bem-estar social, acompanhado pela derrocada das experiências socialistas e a crescente transnacionalização das economias, estas articuladas em torno do capitalismo financeiro (FRIGOTTO, 2009). É nesse cenário que prospera o ideário inclusivista em educação, nos moldes coetâneos do discurso educacional como apaziguador dos conflitos sociais e das crises financeiras endêmicas, fazendo-se das políticas inclusivas uma estratégia de recomposição da hegemonia burguesa e neutralização da barbárie capitalista.

A construção de escolas inclusivas não resulta, em última instância, do esforço político nacional ou da participação ativa dos grupos e representantes de pessoas com deficiência, na luta pela afirmação de seus direitos, mas desenrola-se, sobretudo, como adequação aos critérios internacionalmente estipulados para a concessão de empréstimos e doações. O trecho seguinte ilustra bem a situação, afirmando que

\begin{abstract}
Autoridades nacionais têm a responsabilidade de monitorar financiamento externo à educação especial e, trabalhando em cooperação com seus parceiros internacionais, assegurar que tal financiamento corresponda às prioridades nacionais e políticas que objetivem atingir educação para todos. Agências bilaterais e multilaterais de auxílio, por sua parte, deveriam considerar cuidadosamente as políticas nacionais com respeito à educação especial no planejamento e implementação de programas em educação e áreas relacionadas. (UNESCO, 1994, n.p., grifos nossos)
\end{abstract}

A Declaração de Salamanca tem, nessa direção, um valor indispensável para os estudos histórico-críticos da proposta inclusivista, sobretudo quando se restringe o foco à inclusão de alunos com deficiência. É importante mencionar que a incorporação da educação especial "[...] como parte integrante do sistema educativo [regular]" (UNESCO, 1990, n.p.), tida como uma meta vagamente delineada pelo texto de Jomtien, no rol das estratégias gerais para a universalização equitativa da educação básica (UNESCO, op. cit.), adquire nítidos contornos no documento de Salamanca. Neste, aparece pela primeira vez o conceito de escola inclusiva, tal como hoje se vê bastante difundido pelos meios de comunicação, publicações educacionais e planos de diversos governos. De acordo com a definição ali apresentada, escolas inclusivas

[...] deveriam acomodar todas as crianças independentemente de suas condições físicas, intelectuais, sociais, emocionais, linguísticas ou outras. Aquelas [as escolas] deveriam incluir crianças deficientes e superdotadas, crianças de rua e que trabalham, crianças de origem remota ou de população nômade, crianças pertencentes a minorias linguísticas, étnicas ou culturais, e crianças de outros grupos desavantajados ou marginalizados. [...]. No contexto desta Estrutura [de ação em educação especial], o termo "necessidades educacionais especiais" refere-se a todas aquelas crianças ou jovens cujas necessidades educacionais especiais se originam em função de deficiências ou dificuldades de aprendizagem. (UNESCO, 1994, n.p.) 
Todavia, conforme a análise vem apontando, seria ingênuo pensar que a Declaração de Salamanca surge unicamente em virtude do súbito reconhecimento internacional das necessidades educacionais e sociais das pessoas com deficiência ou outras singularidades, constituindo-se na resposta tardia da sociedade pelos anos de segregação e abandono imputados a esses sujeitos. Do outro extremo, porém, a coerência dialética não permite afirmar, peremptoriamente, que essa dimensão fosse inexistente à época, nem que não tenha passado a existir a posteriori, pois muitas conquistas educacionais, em termos de políticas públicas, puderam ser obtidas após a convenção espanhola. A conjuntura inclusivista trouxe à tona a problemática da exclusão escolar e, assim, projetou os holofotes sobre pessoas até então invisíveis, revelando o polo negativo de uma educação segregadora, mais concentrada nas limitações do que nas potencialidades individuais (VYGOTSKI, 1997), apesar de fazê-lo sem a mediação do materialismo histórico-dialético. A ressignificação da educação especial trouxe, de fato, algumas possibilidades humanizadoras para se repensar o desenvolvimento dos alunos com e sem deficiência em uma mesma sala de aula, sem exceções.

No entanto, o paradigma inclusivo também engendrou outras formas de abandono, negligência, alienação e preconceito, porque não tem levado em conta as incoerências entre o projeto societário existente e o projeto educacional buscado (BARROCO, 2007), promovendo-se a mercantilização das deficiências. Por isso, entendemos que a Declaração de Salamanca institui a inclusão escolar e promove o desmonte da educação especial como locus institucionalizado, não porque estivesse sintonizada com outra concepção de sociedade, oposta ao sistema capitalista. Na verdade, não é objetivo da Declaração pensar a formação do novo homem, para quem a coletividade, livre dos antagonismos de classe e dicotomias reducionistas entre normal versus anormal, seria, finalmente, a fonte máxima de desenvolvimento psíquico e compensação social aos limites pessoais (BARROCO, 2007; VYGOTSKI, 1997, 2004).

O movimento inclusivista, ao contrário, surge e se mantém atrelado aos princípios neoliberais de uma escola e Estado mínimos, obedientes às regras do jogo mercantil, que não reconhece fronteiras éticas ou étnicas, nem assume como referência principal a humanização do homem. Antes, sua meta precípua é a acumulação financeira de poucos e o corte de despesas em detrimento de muitos. Tanto que sequer parecem questionáveis os interesses subjacentes a esta afirmação do documento, segundo a qual "[...] tais escolas [inclusivas] proveem uma educação efetiva à maioria das crianças e aprimoram a eficiência e, em última instância, o custo da eficácia de todo o sistema educacional" (UNESCO, 1994, n.p. grifos nossos).

A inclusão de alunos com deficiência e outras necessidades educacionais é pensada em termos de custo-benefício e eficiência administrativa. O fim último é 
o aprimoramento dos sistemas educacionais, com o intuito de se "[...] impedir o desperdício de recursos e o enfraquecimento de esperanças [...]" (idem, ibid.). A Declaração ainda ressalta que "A experiência, principalmente em países em desenvolvimento, indica que o alto custo de escolas especiais significa, na prática, que apenas uma pequena minoria de alunos, em geral uma elite urbana, se beneficia delas" (idem, ibid.). Não discordo de que as escolas especiais realmente restringissem o número de alunos atendidos, até pelas características do trabalho realizado, intensivo e individual. Certamente, nesse processo, os custos também se tornam muito mais elevados do que a simples inserção dos alunos com deficiência nas salas de aula comum, ainda que contem com a possibilidade de frequentar salas de recursos multifuncionais no contraturno. Nessas salas, segundo a crítica de Glat e Pletsch (2011, p. 25),

[...] é oferecido simultaneamente "atendimento das diversas necessidades educacionais especiais e para desenvolvimento das diferentes complementações ou suplementações curriculares" (ALVES, 2006, p. 14). Isso implica, certamente, que o professor deve ser capacitado para trabalhar com alunos com diferentes condições - o que, realisticamente, é pouco viável.

Diante das considerações apresentadas, o que mais perturba é, portanto, o aspecto de negócio atribuído à escola inclusiva, transformando-se a deficiência em mercadoria, cujos gastos de manutenção no sistema (re)produtivo devem ser minimizados ao máximo, sob a aparência de se defenderem princípios humanistas e "[...] valores inclusivos que se referem à igualdade, à participação, à comunidade, à compaixão [sic], ao respeito pela diversidade, à sustentabilidade [sic!] e ao direito" (AINSCOW, 2009, p. 19). Tais reflexões vêm reforçar a tese de que o ideário inclusivista não emerge dos anseios imediatos das pessoas com deficiência por reconhecimento público e afirmação de seus direitos sociais, embora, para obter consenso, esse ideário englobe tais reivindicações, verdadeiramente legítimas. Entretanto, de início, a tendência inclusivista surge mais como ação e discurso estrategicamente antecipados pela burguesia. A política solidária de inclusão emerge das águas turvas do oceano neoliberal como medida preventiva para cercear ondas revolucionárias que a classe dominante não pudesse dominar; ou transformar em mecanismo de (auto)preservação e administração do capital em crise, constantemente ameaçado pela iminência de colapsos financeiros incontroláveis, agravados pelo esgotamento dos recursos naturais (MÉSZÁROS, 2010).

O neoliberalismo faz da luta universal pela humanização e emancipação do homem, com ou sem deficiência, da luta por seu pleno desenvolvimento junto à coletividade (VYGOTSKI, 1997) e à comunidade real (MARX; ENGELS, 2007), uma luta privatizada, da qual a burguesia é a acionista majoritária, impondo seus interesses à humanidade, enquanto "[...] cria um mundo à sua imagem e semelhança" (MARX; 
ENGELS, 2000, p. 80). As declarações de Jomtien e Salamanca, além de outros documentos legitimadores do ideário inclusivista, como o relatório Jacques Delors (1998), são exemplos do mundo forjado segundo o desejo de organismos internacionais e seus altos representantes burgueses. Juntos, ratificam a inclusão precária e alienante, "[...] a universalidade alienada, unilateral e abstrata do capitalismo [...]" (DUARTE, 2001, p. 151), longe de permitirem, conforme a interpretação de Duarte (op. cit.) sobre o pensamento marxiano, "[...] o desenvolvimento multilateral e universal da individualidade, como consequência do caráter também multilateral e universal das relações sociais" (idem, ibid.).

O aprender a viver juntos, como dimensão humanitária do aprender a aprender, apregoa a harmonia na convivência humana, a beleza do estar com o outro, a necessidade de aceitação e valorização positiva das diferenças. No entanto, promove o conformismo capitalista e a adesão tácita aos (contra)valores do respectivo modelo econômico, para o qual é importante que as pessoas se conformem com sua "diferença". O resultado tem sido a apropriação particular das objetivações genéricas mais enriquecedoras já produzidas pela humanidade; a tolerância, que escamoteia os privilégios e as desigualdades sociais; a emulação levada às últimas consequências. Na tentativa de se assegurar a mínima coesão ao mundo em ruínas, busca-se alardear um consenso ideológico superestrutural, contraditório à própria base material excludente e individualista do sistema. Com o propósito de escamotear a realidade, o poder hegemônico lança mão de uma ideologia que, como falsa consciência, desconsidera ser desta base material adversa o locus donde partem os homens reais e vivos (MARX; ENGELS, 2007), nas condições concretas de sua existência contemporânea. É neste cenário antagônico que se projeta e busca se firmar, hoje, a escola inclusiva. Por conseguinte, o debate em torno do assunto está longe de terminar, demandando estudos mais aprofundados e totalizantes.

\section{Considerações finais}

No presente artigo não puderam ser abordados todos os aspectos críticos acerca da inclusão escolar em sua vertente neoliberal, dados os limites inerentes a este texto, bem como pelo fato de que os resultados da pesquisa ainda são parciais. As reflexões ora realizadas focaram, em especial, os anos de 1990. Nesse período, são oficializadas estas duas declarações, de abrangência mundial, relacionadas ao movimento da escola para todos, sejam pessoas com ou sem deficiência: a Declaração Mundial sobre Educação para Todos: satisfação das necessidades básicas de aprendizagem (UNESCO, 1990) e a Declaração de Salamanca sobre Princípios, Políticas e Práticas na área das Necessidades Educativas Especiais, à qual se integra a Estrutura de Ação em Educação Especial (UNESCO, 1994). A análise de ambas, aqui somente esboçada, permite 
entender mais de perto as proposições e pressupostos ideológicos do ideário inclusivista e como este tem repercutido no cenário educacional, alinhado aos interesses neoliberais.

De uma perspectiva crítico-marxista, consideramos relevante situar esse ideário no bojo das contradições referentes à reprodução sociometabólica do capital (MÉSZÁROS, 2010), conforme objetivadas nos últimos decênios. Entendemos que a análise crítica acerca das questões educacionais, como a inclusão escolar de pessoas com deficiência, não pode dispensar o debate econômico e político, vale dizer, as interfaces entre estrutura e superestrutura. A educação também possui sua Economia Política e sua Política Econômica, das quais o pensamento deve se ocupar para atingir o concreto pensado, a rica totalidade de inúmeras relações e determinações tão almejada por Marx (1999). De acordo com Saviani (2005, p. 17), “Não é possível, portanto, compreender radicalmente a história da sociedade contemporânea e, consequentemente, a história da educação contemporânea sem se compreender o movimento do capital". Foi esta a démarche que tentamos seguir no decorrer do texto, dando, talvez, a impressão de pessimismo e descrença sobre quaisquer propostas de inclusão social e escolar hoje existentes.

Na realidade, pretendemos evidenciar que, se as lutas pela transformação revolucionária têm sido privatizadas e mercantilizadas pelas classes dominantes, a tarefa histórica a ser enfrentada é combater essa apropriação indevida, mediante a defesa de uma concepção socialista de homem, escola e sociedade. Cremos que, a partir das proposições marxistas e marxianas, poder-se-á reinterpretar o conceito de escola inclusiva, pensando-se em seus limites e possibilidades, especialmente enquanto ela estiver presa à engrenagem capitalista. A mediação deste referencial dialético na pesquisa em educação possibilita ao menos vislumbrar, para o presente e para o futuro, perspectivas teórico-metodológicas mais humanizadoras para a formação dos alunos com e sem deficiência.

Logo, a finalidade da análise proposta não é impedir esperanças, mas ampliá-las, tendo como ponto de partida o horizonte visto além das grades capitalistas, porquanto a escola genuinamente inclusiva, na falta de uma expressão mais adequada, não pode objetivar-se senão como possibilidade, enquanto estiver aprisionada no interior desse modelo. Todavia, o fato assim entendido não nos dispensa da tarefa histórica de propiciar a todos os alunos, sem negligenciar a singularidade ontogenética daqueles que tenham alguma deficiência e as implicações disso para a prática docente, mediações pedagógicas que os aproximem do universo cultural o mais amplo e enriquecedor possível. Na esteira dessas considerações, é oportuno evocar um dos belos pensamentos de Karl Marx. Como disse o filósofo na Introdução à Crítica da Filosofia do Direito de Hegel (2008, p. 6), originalmente publicada em 1844, "A crítica colheu nas cadeias as flores imaginárias, não para que o homem suporte as 
cadeias sem fantasia ou sem consolação, mas para que lance fora as cadeias e colha a flor viva".

Trabalhar para essa colheita, buscando as flores vivas, é, pois, o fim para o qual devem se voltar os esforços e estudos na pesquisa em educação, conquanto se pretenda, na atual conjuntura, divisar uma práxis transformadora, para além do capital e suas concessões paliativas, envoltas em apelos pseudo-humanistas. Uma práxis em que a "inclusão" não seja mera acomodação reformista, imposta de forma alienada às escolas, mas sim pretexto para a crítica e subversão da própria (des) ordem (neo)liberal vigente; oportunidade para se almejar, e construir, " [...] um sistema de educação que lhes assegure [a todos os homens, com ou sem deficiência] um desenvolvimento multilateral e harmonioso que dê a cada um a possibilidade de participar enquanto criador em todas as manifestações de vida humana" (LEONTIEV, 1978, p. 284).

Temos a clareza de que, em si mesmos, o embate crítico ao ideário inclusivista e a denúncia de sua filiação aos objetivos reprodutivistas do capital não bastam, embora este seja passo importante e até decisivo para a transformação social e escolar, como defendido anteriormente. Nesse sentido, pensamos que, sendo as ilusões e suas cadeias duramente combatidas, por meio de um esforço teórico para a interpretação desmistificada do real, poderá desabrochar, pelas sendas da História, o desejo pela flor viva, vale dizer, pela ação humana revolucionária.

\section{Nota}

1. Unesco é a sigla de Organização das Nações Unidas para a Educação, a Ciência e a Cultura. Unicef significa Fundos das Nações Unidas para a Infância. UNPD é Programa das Nações Unidas para o Desenvolvimento e costuma aparecer, em iniciais da língua portuguesa, como PNUD.

\section{Referências}

AINSCOW, M. Tornar a educação inclusiva: como esta tarefa deve ser conceituada? In: FÁVERO, O. et al. (Org.). Tornar a educação inclusiva. Brasília, DF: Unesco; ANPEd, 2009. p. 11-23. Disponível em: <http://unesdoc.unesco.org/images/0018/001846/184683por. pdf>. Acesso em: 13 dez. 2011.

ALVES, D.O. (Org.). Sala de recursos multifuncionais: espaços para o atendimento educacional especializado. Brasília, DF: MEC, 2006.

BARROCO, S.M.S. A educação especial do novo homem soviético e a psicologia de L. S. Vigotski: implicações e contribuições para a psicologia e a educação atuais. 2007. 414 f. Tese (Doutorado em Educação Escolar) - Faculdade de Ciências e Letras, 
Universidade Estadual Paulista Júlio de Mesquita Filho, Araraquara. Disponível em: <http://www.dominiopublico.gov.br/download/texto/cp042915.pdf>. Acesso em: 22 fev. 2010.

BEZERRA, G.F. Inclusão e exclusão social: um breve diálogo com educadores. In: ARAUJO, D.A.C.; BERTOLETTI, E.N.M. (Org.). Inclusão social e educação: diferentes perspectivas. Paranaíba: Uems, 2011. p. 35-45. (no prelo).

BEZERRA, G.F; ARAUJO, D. A. C. As aparências enganam: a pretexto de uma crítica radical sobre o ideário inclusivista. Educere et Educare - Revista de Educação, Cascavel, v. 5, n. 9, p. 253-266, jan.-jun. 2010. Disponível em: <http://e-revista.unioeste. br/index.php/educereeteducare/article/view/2690>. Acesso em: 21 abr. 2011.

BEZERRA, G.F; ARAUJO, D.A.C. De volta à teoria da curvatura da vara: a deficiência intelectual na escola inclusiva. Educação em Revista, Belo Horizonte, v. 27, n. 2, p. 277-302, ago. 2011. Disponível em: <http://www.scielo.br/pdf/edur/v27n2/a13v27n2. pdf>. Acesso em: 21 dez. 2011.

CASSIN, M. Louis Althusser: referências para pesquisa em educação. In: LOMBARDI, J.C.; SAVIANI, D. (Org.). Marxismo e educação: debates contemporâneos. 2. ed. Campinas: Autores Associados; Histedbr, 2008. p. 161-179.

DELORS, J. (Org.). Educação: um tesouro a descobrir. São Paulo: Cortez; Brasília, DF: MEC; Unesco, 1998. (Relatório da Unesco para a Comissão Internacional sobre Educação para o Século XXI). Disponível em: <http://www.dhnet.org.br/dados/ relatorios/a_pdf/r_unesco_educ_tesouro_descobrir.pdf>. Acesso em: 1ํo dez. 2011.

DUARTE, N. Vigotski e o "aprender a aprender": crítica às apropriações neoliberais e pós-modernas da teoria vigotskiana. 2. ed. rev. e ampl. Campinas: Autores Associados, 2001.

FRIGOTTO, G. Estruturas e sujeitos e os fundamentos da relação trabalho e educação. In: LOMBARDI, J.C.; SAVIANI, D.; SANFELICE, J.L. (Org.). Capitalismo, trabalho e educação. 3. ed. Campinas: Autores Associados; Histedbr, 2005. p. 61-74.

FRIGOTTO, G. Os delírios da razão: crise do capital e metamorfose conceitual no campo educacional. In: GENTILI, P. (Org.). Pedagogia da exclusão: crítica ao neoliberalismo em educação. Trad. de Vânia Paganini Thurler e Tomaz Tadeu da Silva. 16. ed. Petrópolis: Vozes, 2009. p. 73-102.

GENTILI, P. Adeus à escola pública: a desordem neoliberal, a violência do mercado e o destino da educação das maiorias. In: GENTILI, P. (Org.). Pedagogia da exclusão: crítica ao neoliberalismo em educação. Trad. de Vânia Paganini Thurler e Tomaz Tadeu da Silva. 16. ed. Petrópolis: Vozes, 2009. p. 215-237. 
GLAT, R.; PLETSCH, M.D. Inclusão escolar de alunos com necessidades educacionais especiais. Rio de Janeiro: Eduerj, 2011. (Pesquisa em educação).

GRAMSCI, A. Concepção dialética da história. Trad. de Carlos Nelson Coutinho. 10. ed. Rio de Janeiro: Civilização Brasileira, 1995.

KUENZER, A.Z. Exclusão includente e inclusão excludente: a nova forma da dualidade estrutural que objetiva as novas relações entre educação e trabalho. In: LOMBARDI, J.C.; SAVIANI, D.; SANFELICE, J.L. (Org.). Capitalismo, trabalho e educação. 3. ed. Campinas: Autores Associados; Histedbr, 2005. p. 77-95.

LEONTIEV, A.N. O desenvolvimento do psiquismo. Trad. de Manuel Dias Duarte. Lisboa: Livros Horizonte, 1978.

LOMBARDI, J.C. Apresentação. In: LOMBARDI, J.C.; SAVIANI, D. (Org.). Marxismo e educação: debates contemporâneos. 2. ed. Campinas: Autores Associados; Histedbr, 2008. p. vii-xxviii.

MARX, K. Para uma crítica da economia política. Ridendo Castigat Mores: Rocket, 1999. Disponível em: <http://www.ebooksbrasil.org/adobeebook/criticadaeconomia.pdf>. Acesso em: 21 dez. 2011.

MARX, K. Para a crítica da filosofia do Direito de Hegel: introdução. Trad. de Artur Morão. Covilhã: LusoSofia, 2008. Disponível em: <http://www.lusosofia.net/textos/marx_ karl_para_a_critica_da_filosofia_do_direito_de_hegel.pdf >. Acesso em: 20 dez. 2011.

MARX, K.; ENGELS, F. Manifesto do Partido Comunista. 9. ed. São Paulo: Global, 2000.

MARX, K.; ENGELS, F. A ideologia alemã. Trad. de Luis Claudio de Castro e Costa. 3. ed. São Paulo: Martins Fontes, 2007.

MÉSZÁROS, I. A educação para além do capital. Trad. de Isa Tavares. 2. ed. São Paulo: Boitempo, 2008.

MÉSZÁROS, I. Atualidade história da ofensiva socialista: uma alternativa radical ao sistema parlamentar. Trad. de Paulo Cezar Castanheira. São Paulo: Boitempo, 2010.

NEGRÃO, J.J. Consenso de Washington. In: NEGRÃO, J.J. Para conhecer o neoliberalismo. [S.1.]: Publisher Brasil, 1998. p. 41-43. Disponível em: <http://www.cefetsp.br/ edu/eso/globalizacao/consenso.html>. Acesso em: 30 nov. 2011.

SAVIANI, D. Transformações do capitalismo, do mundo do trabalho e da educação. In: LOMBARDI, J.C.; SAVIANI, D.; SANFELICE, J.L. (Org.). Capitalismo, trabalho e educação. 3. ed. Campinas: Autores Associados; Histedbr, 2005. p. 13-24.

TORRES, C.A. Estado, privatização e política educacional: elementos para uma crítica ao neoliberalismo. In: GENTILI, P. (Org.). Pedagogia da exclusão: crítica ao 
neoliberalismo em educação. Trad. de Vânia Paganini Thurler e Tomaz Tadeu da Silva. 16. ed. Petrópolis: Vozes, 2009. p. 103-128.

UNESCO. Declaração mundial sobre educação para todos: satisfação das necessidades básicas de aprendizagem. Jomtien, 1990. Disponível em: <http://unesdoc.unesco.org/ images/0008/000862/086291por.pdf>. Acesso em: 2 dez. 2011.

UNESCO. Declaração de Salamanca sobre princípios, políticas e práticas na área das necessidades educativas especiais e estrutura de ação em educação especial. Salamanca, 1994. Disponível em: <http://portal.mec.gov.br/seesp/arquivos/pdf/salamanca.pdf >. Acesso em: 2 dez. 2011.

VYGOTSKI, L.S. Obras escogidas: fundamentos de defectología. Trad. de Julio Guillermo Blank. Madrid: Visor, 1997. (Aprendizaje, v. 129).

VYGOTSKY, L. S. A transformação socialista do homem. Trad. de Nilson Dória. [S.l.]: Marxists Internet Archive, 2004. Disponível em: <http://www.marxists.org/portugues/ vygotsky/1930/mes/transformacao.htm> . Acesso em: 6 set. 2009.

Recebido em 6 de fevereiro de 2012.

Aprovado em 26 de março de 2013. 